\title{
POR UMA PEDAGOGIA
}

DECOLONIAL: UMA ANÁLISE

CRÍTICA DE DISCURSOS

SOBRE EDUCAÇÃO EM TEXTOS

LITERÁRIOS EM LÍNGUA

INGLESA E O QUE

ELES ENSINAM

\author{
Fernanda Mota PEREIRA (D) $\boldsymbol{\Delta}$
}

Instituto de Letras - Universidade Federal da Bahia (UFBA)

ఠ

OPEN ACCESS

EDITADO POR

- Miguel Oliveira, Jr. (UFAL)

- René Almeida (UFS)

REVISADO POR

- Maria F. O. Santos (UNEAL)

- Ribamar Jr. (USP)

DATAS

- Recebido: 24/01/2020

- Aceito: 30/03/2020

- Publicado: 02/09/2020

\section{COMO CITAR}

PEREIRA, Fernanda Mota (2020).

Por uma pedagogia decolonial: uma análise crítica de discursos sobre educação em textos literários em língua inglesa e o que eles ensinam Cadernos de Linguística, v. 1, n. 2, p. 01-19.
RESUMO

Este ensaio teórico tem o objetivo de discutir, através de elementos da Retórica (REBOUL, 2000) e da Análise de Discurso Crítica (FAIRCLOUGH, 2012, 2013; MELO, 2018; MAGALHÃES; MARTINS; RESENDE, 2017), sentidos da educação em textos literários, sublinhando as reiteradas tessituras discursivas que compõem a diferença nesses sentidos em textos de escritores negros e não negros. A identificação dessa diferença foi um dos resultados do projeto de pesquisa intitulado "Educação em Narrativas: Experiências em Contextos de Aprendizagem" (PEREIRA, 2016), que mapeou os sentidos da educação em textos literários de língua inglesa produzidos em variados países. Além dessa análise sobre a educação, este ensaio também apresenta argumentos e estratégias de ensino de língua inglesa através da literatura (MOTA, 2010; PEREIRA, 2017) e assinala que o uso dela como recurso didático favorece a implementação de pedagogias decoloniais (WALSH, 2018; OLIVEIRA, 2018). 


\section{ABSTRACT}

This theoretical essay aims to discuss, through elements of Rhetoric (REBOUL, 2000) and Critical Discourse Analysis (FAIRCLOUGH, 2012, 2013; MELO, 2018; MAGALHÃES; MARTINS; RESENDE, 2017), meanings of education in literary texts, underlining the repeated discursive fabrics that make up the difference in these senses in texts by black and nonblack writers. The identification of this difference was one of the results of the research project "Education in Narratives: Experiences in Learning Contexts" (PEREIRA, 2016), which mapped the meanings of education in English-language literary texts produced in several countries. In addition to this analysis of education, this essay also presents arguments and strategies for teaching the English language through literature (MOTA, 2010; PEREIRA, 2017) and points out that its use as a didactic resource favors the implementation of decolonial pedagogies (WALSH, 2018; OLIVEIRA, 2018).

\section{PALAVRAS-CHAVE}

Retórica; Análise de Discurso Crítica; Literatura; Ensino de Inglês; Educação Decolonial.

\section{KEYWORDS}

Rhetoric; Critical Discourse Analysis; Literature; English Teaching; Decolonial Education. 


\section{INTRODUÇÃO}

Este ensaio teórico analisa criticamente discursos sobre a educação em textos literários de escritores de expressão inglesa, usando, para isso, elementos da Retórica (REBOUL, 2000) e da Análise de Discurso Crítica (FAIRCLOUGH, 2012, 2013; MELO, 2018; MAGALHÃES; MARTINS; RESENDE, 2017). A análise tem em perspectiva questões raciais e se vale do insumo derivado dessa articulação para pensar práticas pedagógicas decoloniais (OLIVEIRA, 2018; WALSH, 2018). O intuito é estabelecer a relação entre teoria e prática de forma explícita, assinalando as contribuições da leitura retórica e da análise de discurso crítica para o contexto de sala de aula de língua inglesa ao desvelar as relações de poder e questões socioeconômicas, culturais e raciais como desdobramentos do colonialismo. Esses desdobramentos regem a construção dos sentidos da educação tal como representados em romances, peças e contos de escritores de diferentes países.

A proposta de análise dos textos literários neste ensaio se vale de alguns conceitos da retórica para suscitar a reflexão sobre como determinadas concepções são construídas e a força persuasiva que subjaz aos mais diversos tipos de texto. No que se refere ao uso da análise de discurso crítica, é válido afirmar que este ensaio não se atém aos seus pressupostos metodológicos (MAGALHÃES; MARTINS; RESENDE, 2017), mas permeia essa área, definida por Fairclough (1985 apud MAGALHÃES; MARTINS; RESENDE, 2017, p. 21) "como uma disciplina crítica voltada ao estudo de problemas sociais", por abordar questões raciais no âmbito de uma reflexão sobre educação, tendo em horizonte uma máquina geradora de assimetrias sociais, denominada colonialismo. Os problemas sociais, entre os quais se encontram as questões raciais, podem ser observados em gêneros que, conforme Fairclough (2012, p. 310), "são as maneiras diversas de agir, de produzir a vida social semioticamente". O gênero eleito para flagrar os sentidos da educação é a literatura por abarcar representações sociais e, em seu bojo, ideologias e servir como um meio de propagação delas.

No que se refere à propagação de representações sociais e ideologias, é válido afirmar que as que mais comumente são propagandas são aquelas oriundas do Norte Global (SANTOS, 2019) e, portanto, de matriz eurocêntrica. Esse predomínio resulta da recorrência de textos literários e de outras mídias produzidos nesse polo de poder que, por estar em uma posição de privilégio, é o lugar onde se encontram os autores e os beneficiados das ideologias responsáveis pela construção de hierarquias. Nisso reside a importância da decolonialidade (MIGNOLO; WALSH, 2018; OLIVEIRA, 2018; SANTOS, 2019), que desloca a centralidade de conhecimentos, padrões e modos de existência engendrados por eixos hegemônicos que dividiram, por uma linha abissal (SANTOS, 2019), a metrópole das colônias e disseminaram um sistema estrutural que o atravessou e figura como uma de suas reverberações, ou seja, a colonialidade. 
De acordo com Maldonado-Torres (2007, apud Oliveira 2018), a colonialidade é um dos desdobramentos do colonialismo, tendo como principais símbolos o sistema capitalista e a noção de raça. Boaventura Santos (2019) acrescenta a esses dois aspectos o patriarcado. Mesmo com o fim do colonialismo, a colonialidade que o erigiu continua através de vários mecanismos, da educação formal aos projetos de vida individuais. Esses mecanismos podem ser vislumbrados nos textos literários contemplados neste ensaio. Foram enfocados quatro textos selecionados entre os demais que fazem parte da pesquisa da qual resultam as reflexões neste ensaio. Na análise, ganha destaque a questão racial, que "é sempre vista como periférica graças à visão eurocêntrica dos problemas brasileiros” (OLIVEIRA, 2018, p. 37).

Ao articular a Análise de Discurso Crítica, a Retórica e a Decolonialidade para refletir sobre a educaçãa, espera-se que essa articulação promova o alicerce à construção de princípios de uma pedagogia decolonial (WALSH, 2018). De acordo com Walsh (2018), essa pedagogia, de inspiração em pensadores como Paulo Freire, mas indo além dele ao abordar questões étnico-raciais, por exemplo, não contemplados em suas reflexões, e uníssona às reflexões de bell hooks e Frantz Fanon, tem como princípio uma prática contínua e reflexiva que leva à crítica e à (re)configuração de conhecimentos, estando atenta às necessidades e aos repertórios de saberes dos aprendizes. É uma pedagogia que se move em prol da liberdade de pensamento não apenas no plano individual, mas, também, coletivo, assumindo uma posição de engajamento em que a qualidade de vida e a equidade são uma meta.

Nota-se que a proposta que está no bojo dessa pedagogia em nada se afina aos objetivos neoliberais e capitalistas, arvorados na competitividade e na produtividade guiadas por uma excelência que exclui o bem-estar, a solidariedade e o senso de comunidade (GIROUX, 2014; WRIGHT, 2019). Nos textos literários pesquisados para este ensaio, há duas concepções principais de educação, compondo uma linha divisória traçada por um viés racial. De um lado, nota-se a concepção de educação como elemento de transformação individual com reflexos no plano social por serem os sujeitos representantes de expectativas de sua comunidade e por romperem ciclos sociais de exclusão em que pessoas como eles não figuravam em conquistas no campo educacional e em outras instâncias da sociedade. De outro, veem-se sujeitos que buscam conquistas individuais e para quem as condições daqueles que pertencem à mesma comunidade não têm relevância.

Para abordar as questões tratadas neste ensaio, ele divide-se em três partes principais. A primeira contempla uma discussão sobre os pressupostos teóricos da Retórica, Análise de Discurso Crítica e Decolonialidade. A segunda parte traz a leitura de textos literários, enfocando sentidos da educação nesses textos e o que eles ensinam. Na terceira seção, são tecidas propostas para uma pedagogia decolonial, tendo a literatura como recurso didático. 


\section{ANÁLISE CRÍTICA DE DISCURSOS DA EDUCAÇÃO: UMA QUESTÃO DE RETÓRICA}

Em diferentes épocas, textos literários encenam histórias de personagens cujas vidas são marcadas por experiências de ensino e aprendizagem. Neles, é possível flagrar uma concepção de educação que traduz epistemologias ao mesmo tempo em que atuam em sua consolidação por trazerem, em seu cerne, um aspecto que é inerente a diversos textos, mesmo quando apenas voltados à demonstração: a persuasão. Para Fiorin (2018a), mesmo esses tipos de texto apresentam um sentido de convencimento, pois se inserem no que pode ser concebido como comunicação. Segundo o autor (2018a, p. 75), "[a] finalidade última de todo ato de comunicação não é informar, mas persuadir o outro a aceitar o que está sendo comunicado". O ato de comunicar, desse modo, não consiste em uma mera apresentação de informações, mas na transposição de um sentido que o enunciador almeja levar o enunciatário a "crer". (FIORIN, 2018a, p. 75) Essa mesma noção é extensiva à literatura e potencializada pela sua linguagem, que demanda do leitor um exercício constante de interpretação e envolvimento com a história que se desvela a cada página.

A noção de persuasão assinalada por Fiorin (2018a) estende-se à eleição de uma gama de textos e conteúdos, traduzida no que convencionalmente se conhece como currículo ou cânone ou lista de indicação de leituras, que também se volta a persuadir sobre conhecimentos, valores e padrões. Tal eleição é regida por mecanismos de poder e suas relações e esses fazem parte do escopo da Análise de Discurso Crítica (MELO, 2018; MAGALHÃES; MARTINS; RESENDE, 2017).

Não é difícil estabelecer uma relação entre retórica e estudos do discurso ao pensar nas três disciplinas que compunham os estudos linguísticos na Antiguidade e Idade Média, a saber: "a dialética, a retórica e a gramática" (FIORIN, 2018b, p. 12). Enquanto a dialética se volta a discernir o que é verdadeiro ou não nas representações e a gramática se debruça sobre os elementos que compõem os enunciados, "[a] retórica estuda os meios de persuasão criados pelo discurso e analisa, nos enunciados, os efeitos que eles podem produzir nos ouvintes”. (FIORIN, 2018b, p. 12) Essa definição de retórica encontra na concepção de Análise de Discurso Crítica convergências claras, uma vez que esse campo tem como alvo "efeitos ideológicos que os sentidos de textos, como instâncias de discurso, podem ter sobre as práticas sociais" (MELO, 2018, p. 23). Desse modo, é possível pensar a combinação entre as ideologias e as relações de poder tal como engendrada em variados textos, a exemplo dos literários, como meio de persuasão cujos reflexos são observados na sociedade. As práticas sociais, por sua vez, envolvem um processo dinâmico que assinala que realidades, identidades e relações não são pré-estabelecidas, mas, sim, construções. De acordo com Melo (2018, p. 23), "para a ADC, o mundo não nos é dado, mas o formulamos num fluxo de nossas 
interações sociais, que formam, através de práticas discursivas, versões da realidade que se realizam na linguagem, e não a partir dela." Para que o discurso presentifique uma realidade, a persuasão é um componente fundamental. Se a realidade não é um dado préexistente, é importante investigar os mecanismos que constituem essas versões e fazem parte da "arte de persuadir pelo discurso" (REBOUL, 2000, p. XIV), chamada Retórica. Acredita-se que um dos mecanismos capazes de presentificar a persuasão a serviço de discursos hegemônicos e também desconstruí-los é a literatura.

Em suas considerações sobre retórica, Fiorin (2018b) mostra como elementos retóricos estão presentes em diversos tipos de texto e, por extensão, discursos, entre os quais destaca a literatura (2018b), usada em vários exemplos. Ele se debruça sobre as figuras de retórica que, se outrora eram tidas apenas como forma de ornamentar a expressão de algo, são vistas por ele como um dos elementos para argumentação, por serem "formas da língua" (FIORIN, 2018b, p. 10) e, como tal, terem o propósito de "produzir sentidos". (FIORIN, 2018b, p. 10).

O poder retórico da literatura é reconhecido por Chinua Achebe (2000) ao afirmar que uma das estratégias de dominação de um povo é ter um contador de histórias que possa narrar a sua incapacidade de se autogovernar. Essa foi a estratégia usada pelo colonialismo e mantida pela colonialidade, como denota o grande acervo de textos europeus, incluindo os de filósofos como Kant, Hegel, Durkheim (OLIVEIRA, 2018) e uma literatura que retrata a África de "uma forma muito negativa" (ACHEBE, 2009, tradução nossa).

Um conjunto de textos literários e de outros gêneros produzidos na Europa constituiu discursos sobre as ex-colônias que imprimiram um modo de ver o que não pertence ao Norte Global como inferior e seus sujeitos como menos humanos (SANTOS, 2019). A arquitetura dessa produção de discursos e a ausência de espaço para textos produzidos nos países colonizados favoreceram o estabelecimento de modos de saber e de existir que resvalaram para as margens o que escapava à centralidade europeia.

Há algumas décadas, o predomínio secular de conhecimentos e padrões eurocentrados tem sido cada vez mais problematizado. Dessa problematização, emergem as teorias em torno da decolonialidade (MIGNOLO, 2018; WALSH, 2018; OLIVEIRA, 2018), cujas contribuições podem redimensionar aquela que talvez seja a área mais efetiva para desconstruir paradigmas e práticas coloniais: a educação. Para isso, advoga-se, neste ensaio teórico, por uma Pedagogia Decolonial e entende-se que a retórica e a análise de discurso crítica oferecem elementos para subsidiá-la no tocante à conscientização sobre os mecanismos de poder que regem os sentidos da educação e podem ser flagrados na malha discursiva de textos literários. Por sentidos, compreende-se não só o que a educação representa para os sujeitos aprendizes, mas, também, a que ideologia(s) ela atende.

Um primeiro olhar sobre a articulação entre Retórica e Pedagogia Decolonial pode considerar dissonante a relação entre um campo teórico convencionalmente associado ao 
estudo de textos canônicos e de tradição clássica, como a Retórica, e o campo dos estudos decoloniais, que deslocam as bases que promovem e legitimam o cânone. Todavia, acionar a retórica como instrumental para pensar sentidos da educação em textos literários é um modo de operar uma rasura na inclinação de afinar instrumentais teóricos a determinados objetos ou reforçar o hermetismo de campos do conhecimento. Além disso, com o tempo, os estudos de Retórica passaram a contemplar variados tipos de texto.

Apesar das reconfigurações pelas quais a Retórica passou, ainda é possível encontrar, no senso comum, o uso do termo "retórico" atrelado a "coisa empolada, artificial, enfática, declamatória, falsa" (REBOUL, 2000, p. XIII). Essas denotações presentes no senso comum não são aleatórias e remontam à época de constituição da Retórica como arte.

Definida, ainda na Antiguidade, como a arte de persuadir, a retórica teve em Platão, filósofo que simboliza a busca pela verdade, um dos seus opositores. A sua aversão resultava da ênfase, nessa arte, sobre seu exercício pela busca da persuasão e não da verdade. Em A República, Platão (2000) revela oposição à outra arte que viria a ser denominada literatura sob o argumento de que ela ludibriava os sentidos, levando a ver como verdadeiro algo que se construía no território do ficcional. Tal argumento afina-se ao seu apreço pela verdade.

A episteme platônica encontra na visão aristotélica um ponto de redimensionamento. Ao invés de abordar apenas a "verdade", Aristóteles (1996) apresenta a verossimilhança. Assim, para ele, a arte poética, ou seja, a literatura, e a Retórica recebem um status distanciado daquele atribuído por Platão. A partir da visão aristotélica, é possível pensar a noção de que o que é passível de se conceber como "verdade" não é um dado pré-existente, mas, sim, uma construção.

Na contemporaneidade, a discussão sobre discursos verdadeiros ou falsos reencena a questão platônica e aristotélica. Nela, a retórica incide como área capaz de levar a compreender como os discursos são produzidos com o intuito de persuadir. Para isso, evocamse os três pilares de arquitetura discursiva relacionados a ela, a saber: etos, patos e logos (REBOUL, 2000). Etos se refere ao caráter do enunciador, construído através do seu discurso. Patos, por sua vez, denota a imagem que se constrói do enunciatário com base na interpretação que o enunciador tem dele. O logos, por fim, se refere à construção do raciocínio e argumentação. Nesses três pilares que se inter-relacionam, destaca-se o patos como um dos principais fatores que, na cena brasileira atual, tem promovido a persuasão.

Na era das notícias falsas, as chamadas fake news, a identificação dos perfis dos possíveis enunciatários e suas paixões - palavra que deriva do termo patos - figura como um componente mais importante do que a construção do caráter do enunciador, por vezes, até mesmo anônimo. A legitimação das fake news poderia ser vista sob o prisma aristotélico que abarca a noção de que o discurso é o componente responsável por construir a verdade quando verossímil (ARISTÓTELES, 1996), ou seja, quando há elementos para ser 
considerado plausível. Entretanto, flagram-se, nessas produções discursivas, aspectos inverossímeis que, mesmo sendo-o, conseguem persuadir o enunciatário. Assim, o discurso, ainda que incoerente, será eficaz se contemplar as paixões dos enunciatários e essas paixões, alicerces do devaneio, ajudarem a construir do improvável a "verdade".

No âmbito da reflexão sobre essas paixões, destaca-se a ausência do componente capaz de expurgar afecções e sentimentos que engendram ações impulsivas: a literatura. Ao discorrer sobre a tragédia, Aristóteles (1996) afirma que esta ao causar "pena e terror opera a catarse própria dessas emoções." (ARISTÓTELES, 1996, p. 36) A pouca ênfase dada à prática de leitura de textos literários e à fruição das artes atua na construção de uma sociedade propensa ao não exercício de interpretação da realidade, da não empatia, da ausência de autoconhecimento e cada vez mais afeita a discursos que situam a educação no território da funcionalidade prática com foco na profissionalização. Ao lado dessa funcionalidade, sublinha-se a meta de primar por um ensino não ideológico, sob a justificativa de que o ensino tem sido regido por uma lógica de esquerda, e a despeito da noção de que "toda pedagogia é retórica" (REBOUL, 2000, p. 104). Desse modo, nenhum ato de ensinar é despido de viés ideológico, pois quem ensina sempre está voltado a persuadir o outro sobre algo e, quando pensa não fazê-lo, o silenciamento em relação a determinados conteúdos em detrimento de outros também enuncia uma ideologia. Afinal, todo conhecimento parte de concepções de sociedade, crenças, modos de existir, princípios, desejos, entre outros fatores que compõem o que se entende por viés ideológico.

O projeto de despolitizar a educação transcende o objetivo de excluir uma agenda partidária, desembocando na meta de enfatizar conteúdos que levam a um conhecimento despido de reflexão e ignoram sujeitos subalternizados historicamente, que passaram a ter voz e vez nos discursos da decolonialidade (WALSH, 2018). Essa premissa encontra ecos na constatação de autores que advogam pelo pensamento crítico, a exemplo de Paulo Freire (2011) e bell hooks (2010), que assinalam uma visão de educação como não dissociada da sociedade e das questões relativas à vida, aos sentimentos. Nesse tipo de educação, o sujeito social ocupa o centro do processo de aprendizagem, contemplando aqueles que foram oprimidos historicamente e cuja emancipação intelectual não interessa ao projeto neoliberal (GIROUX, 2014) que subjaz à demanda por despolitização do ensino.

Esse projeto se encorpa em uma reação à emergência de grupos subalternizados na cena política, da produção acadêmica e das salas de aulas. A presença de índios, negros, travestis, transexuais, gays, lésbicas, entre outros sujeitos que subvertem a lógica eurocêntrica, heteronormativa e patriarcal na produção de conhecimentos, foi lida como uma ameaça às estruturas de poder traduzidas em discursos de normalização de saberes e modos de existir.

A partir do descentramento dessa norma e da possibilidade de serem acessados modos diversos de existência, eclodiu uma forte tessitura retórica, voltada, sub-repticiamente, 
a operar um desvio diante das mudanças conseguidas. Essas manobras têm autoria de sujeitos cujo privilégio de serem os franqueadores dos espaços de fala atrai a população afeita ao propósito de manutenção desse privilégio, por pertencerem a camadas sociais de prestígio, mas também sujeitos que, paradoxalmente, se projetam nos padrões que os excluem. Nota-se, portanto, um paradoxo no uso de uma voz outrora silenciada conclamando a volta do silenciamento.

No bojo do conservadorismo, ao enfocar uma educação que apenas traz ensinamentos que preparam o aluno para o mercado de trabalho, antevê-se uma sociedade acrítica e incapaz de apreender os meandros de um sistema voltado para a reprodução ao invés de produção de conhecimento e insensibilização diante da realidade da maioria da população do país afetada pela desigualdade social. É importante frisar que não se atingiu, de forma universal, um nível de ensino no Brasil capaz de instrumentalizar os sujeitos a identificar esses meandros, mas os avanços foram consideráveis. Por isso, uma contracorrente pautada em um projeto de silenciamento foi soerguida com uma elevada violência discursiva contrária aos avanços, confirmando o movimento pendular da história de avanços e retrocessos.

Sem uma educação que aguce o pensamento crítico, é fácil persuadir sujeitos a aderirem a determinadas ideologias. Nesse tocante, afirma-se que há mais discursos que subsidiam práticas de subalternização do que de emancipação e empoderamento. Esses discursos têm como matriz a colonialidade. De acordo com Maldonado-Torres (2007, p. 131 apud OLIVEIRA, 2018, p. 46), "[a] colonialidade se mantém viva nos manuais de aprendizagem, nos critérios para os trabalhos acadêmicos, na cultura, no senso comum, na autoimagem dos povos, nas aspirações dos sujeitos e em tantos outros aspectos da nossa experiência moderna" (MALDONADO-TORRES, 2007, p. 131 apud OLIVEIRA, 2018, p. 46).

A dimensão alcançada pela colonialidade enuncia a sua reiteração através de diferentes suportes e evidencia sua força retórica, que orquestra atitudes entre as quais nota-se uma aversão aos centros produtores de conhecimento de forma crítica e científica. Como já mencionado, a cena do debate sobre educação tem sido tomada por discussões em torno da chamada "doutrinação ideológica" de estudantes na educação básica e, em especial, no ensino superior.

Os argumentos usados para convencimento da população sobre as ameaças de uma educação doutrinária de "esquerda" construíram uma rede de discursos erguida sobre o medo da perda de padrões que orientam uma sociedade que se vislumbra no território do ideal branco, heteronormativo, patriarcal e capitalista. Entretanto, uma reflexão mesmo não aprofundada sobre a realidade social brasileira demonstra que os princípios que orientam a sociedade estão muito mais alinhados ao capitalismo do que ao socialismo ou ao comunismo, o que dá indícios da inexistência de práticas de ensino orientadas por ideologias de esquerda. 
A demanda pela despolitização da educação aciona a visão de que a educação deve ser utilitária ao invés de dar margem ao que se encontra nas margens do que se concebe como a "verdade". Essa "verdade", na sociedade ocidental, sempre se sustentou através de um paradigma: aquele advindo de epistemologias do Norte (SANTOS, 2019). Em tais epistemologias, não há espaço para a diversidade representada por grupos tradicionalmente oprimidos por estruturas de poder voltadas à manutenção de padrões eurocêntricos.

Houve um empenho, expresso nos requisitos de avaliação dos livros didáticos no Programa Nacional do Livro Didático, para contemplar grupos subalternizados nos livros. Um empenho análogo foi observado na criação das leis 10.639/03 (BRASIL, 2003) e 11.645 (BRASIL, 2008), que instituíram, respectivamente, o ensino compulsório de cultura e história afrobrasileira e de cultura afro-brasileira e indígena. Apesar dessas ações, não foi possível observar uma reversão significativa que assegurasse uma sociedade sem preconceito racial. A impossibilidade de uma reversão não torna menos viável a subversão que ocorreu mediante fissuras nas epistemologias do Norte (SANTOS, 2019).

Essas fissuras servem para problematizar as epistemologias do Norte (SANTOS, 2019) que, por muito tempo, foram assimiladas a ponto de nem ao menos serem questionadas em virtude de um processo de naturalização, que se tornou parte do senso comum. De acordo com Fairclough (2013, p. 62, tradução nossa), "[n]o senso comum, ideologias se tornam naturalizadas, ou automatizadas". Essa naturalização pode ser evidenciada no não questionamento, por muito tempo, sobre a ausência de representações de sujeitos que fogem a padrões eurocêntricos e heteronormativos em salas de aula, na mídia, na literatura que compõe o cânone e em posições de poder.

A partir da emergência de uma ampla discussão sobre variadas formas de opressão e de reflexões sobre a Decolonialidade, práticas de apagamento de epistemologias não eurocêntricas passaram a ser questionadas. Apesar de uma presença mais constante de discussões que envolvem sujeitos outrora não contemplados em aulas no ensino em nível básico e superior, ainda se observa a necessidade de maior investimento nessas discussões até atingir uma guinada substancial que possa desconstruir paradigmas e hierarquias. A solução apontada por pensadores da Decolonialidade não é reverter ou substituir as epistemologias do Norte, mas "ultrapassar a dicotomia hierárquica entre Norte e Sul” (SANTOS, 2019, p. 26).

No processo de subversão e desconstrução dessas hierarquias, a educação figura como uma importante alternativa. Uma das estratégias de subversão de uma educação atravessada pela colonialidade calcada nas epistemologias do Norte é a "conscientização", para usar um termo de Paulo Freire (2011, p. 74), e a interculturalidade (WALSH, 2018), que leve ao diálogo entre culturas diversas, o que inclui a possibilidade de diálogo entre culturas do Norte e do Sul Global. Um dos recursos que dá o suporte para colocar essas duas estratégias em prática é a literatura. É ainda mais profícuo usar esse recurso 
quando ele traz em suas malhas experiências de ensino e aprendizagem e são nelas identificados e analisados diferentes sentidos da educação. A reflexão sobre esses sentidos, quando atenta a questões identitárias, epistemológicas, culturais, raciais, promove uma prática de ensino emancipatória.

No que se refere às aulas de língua inglesa, em que ainda se observa a ênfase na competência linguística ou comunicativa, a ampliação de horizontes que a literatura promove pode tornar as aulas mais significativas e com contribuições para a formação de sujeitos críticos e atentos aos signos que perfazem a realidade e que, quando analisados, levam a uma maior consciência social. Com isso, também, os aprendizes se preparam para a pluralidade cultural em situações de uso do inglês, quer seja no Norte ou no Sul Global.

\section{LITERATURA E O QUE ELA ENSINA SOBRE OS SENTIDOS DA EDUCAÇÃO}

Em 2016, o projeto "Educação em Narrativas: Experiências em Contextos de Aprendizagem" (PEREIRA, 2016) foi elaborado com o objetivo de mapear representações sobre educação em textos literários escritos em inglês. Ao longo da pesquisa, foram analisados textos de escritores da Nigéria, Quênia, África do Sul, Inglaterra, Estados Unidos, Ilhas Salomão, Índia e Irlanda.

A pergunta inicial de pesquisa se referiu à diferença de sentidos da educação em textos literários produzidos em países imperialistas e nas ex-colônias. Entretanto, em um primeiro estudo comparativo, a análise de Youth, do sul-africano J.M. Coetzee (2003), e de Weep Not, Child, do queniano Ngugi wa Thiong'o (2009), engendrou a pressuposição de que a educação recebe uma acepção diferente na literatura de escritores brancos e negros, que se confirmou através do estudo de outros textos literários. Entre os escritores negros pesquisados, a educação figura como agente de transformação social, não concebido sob o prisma individual da busca pelo êxito pessoal, em uma perspectiva neoliberal, como ocorre, por exemplo, com o protagonista de Youth, cujo objetivo é morar em Londres para poder atuar como poeta, seguindo a rota de outros escritores que migraram para a Europa em busca de condições favoráveis para seu desenvolvimento como escritores. Em Weep Not, Child, o protagonista, Njoroge, sonha em ir à escola como modo de não apenas realizar o sonho de aprender, mas, também, como meio de melhorar a vida de sua família. Ele é consciente do ciclo excludente de acessos à educação existente em seu país e sua vontade de estudar rompe esse ciclo. Esse rompimento tem, portanto, reverberações que transcendem o plano individual, porque representa a ascensão onde parece não haver a possibilidade de ela existir. 
Estudar em uma escola predominantemente composta por estudantes brancos é visto como uma conquista: "[p]ara Njoroge, vir para cá era uma espécie de realização de seus sonhos. Ele seria, pela primeira vez, ensinado pelo homem branco" (THIONG'O, 2007, p. 118, tradução nossa). Em outras passagens do romance, questões raciais insurgem e denotam um país marcado pela lacuna socioeconômica entre a população negra que não se aliou aos colonizadores brancos, a que fez essa aliança e a população branca. Nioroge, por exemplo, alude ao ciclo de oportunidades na vida de Jacobo, que faz parte da população negra que se rendeu ao colonialismo, e que era dono das terras onde a família de Njoroge vivia, em contraste com a população subjugada pelo sistema colonial: "[e]u acho que Jacobo é tão rico quanto o senhor Howlands porque ele teve acesso à educação. E é por isso que ele dá educação aos filhos porque obviamente eles aprenderam o valor da educação." (THIONG’O, 2009, p. 4, tradução nossa). O romance demonstra, contudo, que o motivo do enriquecimento de Jacobo não está relacionado apenas à educação. Ele serve aos interesses colonialistas do senhor Howlands mesmo à custa da subjugação da população negra da região que tem como única alternativa cultivar as terras que um dia foram suas e que passaram a pertencer ao colonizador. Todavia, a sua reflexão sobre a educação revela que, para ele, ela representa a única possibilidade de ascensão socioeconômica e, para sua família, o acesso a ela era dificultado pelas restrições financeiras que enfrentavam e que são enunciadas no alerta da mãe de Niroge quando informou que ele iria à escola: "[...] você não terá a refeição do meio dia como as outras crianças". (THIONG'O, 2009, p. 2, tradução nossa) Apesar de todos os desafios, ele queria estudar e conseguiu chegar a uma escola de ensino médio que não era facilmente acessível. A sua experiência contribui para redimensionar as histórias de obstáculos enfrentados por estudantes em situação de vulnerabilidade socioeconômica, mas não deve ser vista como uma regra aplicável a quaisquer sujeitos como se pelo empenho fosse possível superar os desafios impostos pela desigualdade social. Nesse tocante, é válido afirmar, inclusive, que, em certo ponto da narrativa, ele não consegue continuar seus estudos por causa dos conflitos que eclodiram em seu país e que envolveram sua família, confirmando a força que eventos como esse têm sobre a trajetória de estudantes não só no Quênia, mas em outros países marcados por assimetrias sociais e pela violência.

Uma história análoga envolve o personagem Maduru, de The Alternative. Nesse romance, escrito por John Saunana (1980) e ambientado nas Ilhas Salomão, o personagem tem a educação como meio de emancipação social. Ao lutar por ela, ele se nutre de propósitos coletivos, que trazem avanços que beneficiam outras pessoas no contexto de um país marcado pela hegemonia eurocêntrica, que subalterniza a população nativa.

Em No Longer at Ease, do nigeriano Chinua Achebe (2010), a volta do protagonista à Nigéria depois de ter estudado na Europa não é vista como uma conquista pessoal, mas, sim, como uma vitória daquela sociedade. O mesmo sentido parece incidir em histórias de 
sujeitos que ingressaram na universidade como os primeiros de sua comunidade e inspiraram outras pessoas a buscar o nível superior também.

Weep Not, Child, The Alternative e No Longer at Ease apresentam sujeitos que enfrentam condições desfavoráveis impostas pela pobreza - que trazem desafios à aprendizagem (JENSEN, 2009) - e, com isso, constroem uma nova história que possa inspirar outros sujeitos. A ausência de equidade no acesso à educação não é facilmente rompida. Ela tem que superar um discurso de baixa expectativa em relação a alunos não brancos e vulneráveis socioeconomicamente, como aponta bell hooks (2003) em Teaching Community. A Pedagogy of Hope.

Em contraste com o sentido social que a educação tem para sujeitos representados em narrativas de escritores negros, em Pygmalion, do irlandês Bernard Shaw (2016), Eliza Doolittle, que trabalhava como vendedora de flores na rua e falava um inglês não-padrão, ascende socialmente quando passa a ter aulas com o Professor Higgins. Diante do êxito do experimento de Higgins, Eliza almeja voltar à rua onde morava para ostentar sua ascensão para suas amigas que não conseguiram o status que ela conquistou. Tal atitude afina-se a uma lógica capitalista, em que a conquista se torna enaltecida se ela é atingida em detrimento da não conquista alheia, já que um dos pilares desse sistema é a desigualdade.

De acordo com Wright (2019, p. 46), "[é] inerente ao capitalismo a geração de um desigual acesso, em escalas massivas, às condições materiais e sociais necessárias para uma vida plena". As consequências da desigualdade são sentidas por Eliza Doolittle, que se rendeu à precariedade do trabalho de vender flores nas ruas. Todavia, esse capítulo de sua história não a levou a se comover com a situação das pessoas com quem outrora convivia antes de sua ascensão social e para quem desejou, na verdade, ostentar seu novo status.

A visão apresentada em diversos textos lidos nessa perspectiva é passível de refutação diante da apresentação de um texto que contradiga o empreendimento retórico realizado para enunciar a relação entre o significado da educação para sujeitos que não se alinham ao padrão eurocêntrico e aqueles cuja cor da pele foi definidora do conceito de raça, criado a partir da necessidade de nomear o que era diferente do europeu (MBEMBE, 2014). Diante da possibilidade de existência desse texto, é possível apenas antecipar que qualquer reflexão está sujeita aos redimensionamentos promovidos por um ponto de vista ou algum contra-argumento. Entretanto, o exercício crítico de estudo de um determinado universo de pesquisa aponta caminhos que cabe ao pesquisador identificar e, então, tecer os elementos que promovem a coerência necessária para persuadir o leitor sobre a tese. O primeiro elemento de persuasão, contudo, é criado no próprio ato de estudo do universo pesquisado.

Outro importante elemento de persuasão na retórica e nas discussões contemporâneas sobre lugar de fala (RIBEIRO, 2019) é o etos. Nesse tocante, um fator que pode ser pensado como ponto de convencimento sobre a propriedade das reflexões da autora neste ensaio é sua ampla vivência na literatura desde a graduação, a atuação docente e o olhar 
atento a questões raciais, que enunciam um lugar de fala coerente pelo fato de a autora ter vivenciado questões raciais em suas próprias experiências educacionais. Ter esse lugar de fala não é condição sine qua non para entender questões raciais. Contudo, é desse lugar que, a partir de uma reflexão sobre essas questões, elas são entendidas por um filtro que encorpa o pensamento por terem sido parte de múltiplas vivências.

\section{POR UMA PEDAGOGIA DECOLONIAL}

Mesmo em contextos de educação tradicional, o ato de ensinar não é perpassado apenas por práticas de transmissão de saberes. O elenco de conhecimentos eleitos para compor um currículo é orientado por epistemologias. As reiteradas tessituras discursivas presentes nos conteúdos da educação básica, quando analisadas de forma crítica, enunciam a ênfase em saberes que apontam para epistemologias do Norte (SANTOS, 2019).

Para pensadores inseridos no campo de reflexão sobre saberes do Sul e práticas decoloniais, os conhecimentos advindos do Norte e consolidados por conteúdos ensinados nos mais variados centros educacionais não podem ser facilmente deslocados como se, a partir de uma conscientização sobre os mecanismos de poder que os erigiram, fosse possível revertê-los ou rechaçá-los. No entanto, é possível fazer "fissuras" (WALSH, 2018, p. 82, tradução nossa) neles. As fissuras, quando constantes, podem abalar o edifício metafísico erguido por elementos retóricos que enalteceram modos de saber em detrimento de outros.

A emergência de tal edifício pode ser localizada na colonialidade, cuja ressonância mais evidente é o racismo, que não terminou com o fim da escravidão, um sistema no qual se sustentaram as práticas coloniais. Pelo contrário, mesmo com o fim da escravidão, houve um investimento científico para provar que o branco era superior ao negro (VAN DIJK, 2009).

A arquitetura discursiva que argumenta a favor da superioridade branca tem sido alvo de problematização e desconstrução. Todavia, enquanto alguns padrões são revistos, a discussão sobre saberes e formas de ensino que ratificam essa hegemonia ainda é recente e desprovida da amplitude que deveria ter para promover uma mudança de paradigmas. Tais paradigmas ainda definem os espaços de conhecimento de excelência alinhados aos padrões ditados pelos países hegemônicos, que nutrem os Academic Dreams. Esses padrões figuram nos modelos de avaliação das mais diversas instâncias educacionais com ênfase na "eficiência e custo" (BASSO; NETO, 2014, p. 12), conduzidos por uma perspectiva neoliberal.

Em um país com desigualdades abissais como o Brasil, o neoliberalismo é dissonante. A ausência de equidade não permite uma competitividade justa, porque sujeitos em situação de pobreza e afetados por um sistema de discriminação racial estão em condição de 
desvantagem em relação àqueles isentos desses problemas. À competitividade deveria ser sobreposta a noção de comunidade de aprendizagem (HOOKS, 2003), em que a solidariedade é um dos valores em horizonte.

Nutrir o sentimento de cooperação, compartilhamento de saberes e solidariedade é uma forma de humanizar o espaço da sala de aula. É também um modo de primar por uma poética de ensino em que os objetivos se voltam para a construção de uma sociedade em que os diferentes modos de saber e existir sejam vistos como componentes de um trançado de vivências que leva ao crescimento mútuo.

Ao acessar saberes e existências que se distanciam de paradigmas eurocêntricos, nota-se uma riqueza de crenças, visões de mundo e atitudes que teriam muito a contribuir para uma sociedade cuja meta fosse o bem-estar social e a harmonia com as diversas formas de vida. Disso decorre a necessidade de uma pedagogia decolonial (OLIVEIRA, 2018) com o propósito de desconstruir o predomínio de uma cultura, valores e conhecimentos eurocêntricos. De acordo com Oliveira (2018, p. 102),

Uma perspectiva de educação decolonial requer pensar a partir dos sujeitos subalternizados pela colonialidade, como índios, negros, mulheres, homossexuais e outr@s marcadores das diferenças contrapostas às lógicas educativas hegemônicas brancas e eurocentradas.

A educação decolonial é uma questão de práxis que requer um descentramento de epistemologias e padrões engendrados pela colonialidade e que foram consolidados pelo lluminismo e ciência moderna. Nessa práxis, cabe refletir sobre recursos para implementar pedagogias decoloniais. Uma forma de acesso a outros conhecimentos e modos de existência é a arte, sobretudo aquela produzida em países não circunscritos ao eixo hegemônico. Na esfera dessa arte, destaca-se a literatura que, em virtude de um tratamento singularizado de seu modo de expressão, convida o leitor à imersão em histórias que o deslocam do seu lugar comum em virtude das projeções em experiências alheias e às quais, talvez, só poderia ter acesso pelo território da ficção. Ao contemplar a literatura de países não hegemônicos, a sua leitura leva a conhecer realidades não comumente acessadas e que descortinam contextos socioculturais diversos com os quais é possível ampliar o repertório de saberes para além daqueles convencionalmente conhecidos.

Se a literatura promove uma travessia para a diversidade, a imersão constante na literatura de uma matriz específica leva à construção de imaginários capazes de alienar sujeitos, por vezes, até mesmo de sua própria realidade. Um exemplo dessa alienação é narrado por Chimamanda Adichie (2009) em The Danger of a Single Story, em que faz alusão à sua experiência de leitora da literatura europeia, narrando como o imaginário veiculado nela atuava no seu processo de criação de histórias. Essa mesma reiteração de padrões é replicada em estilos de vida e preferências estéticas, deslocados quando passam a serem vistos sob um prisma crítico e atento à diversidade. 
Assim, para uma educação decolonial, propõe-se suplementar os materiais didáticos na sala de aula de língua inglesa com a literatura de escritores negros, que serviria não só como material de leitura, mas também como exemplo para contextualização de assuntos e atividades bem como para depreender deles insumos para prática oral e escrita. É válido enfatizar que as lições depreendidas pela imersão nos imaginários trazidos pelos textos literários se referem não apenas ao conhecimento linguístico, mas, também, a um olhar sobre questões sociais, raciais, culturais e ideológicas. Nesse sentido, a análise crítica de discursos em textos literários de diferentes países ou continentes ou por um recorte temático leva à imersão em aspectos que podem dilatar a perspectiva quanto a questões nem sempre alcançáveis por um olhar voltado a uma mesma categoria de texto ou a uma mesma paisagem.

Artigos que advogam pelo ensino de língua estrangeira através da literatura (GHOSN, 2001; MOTA, 2010; PEREIRA, 2017) apresentam exemplos de estratégias didáticas em que ela figura como um profícuo recurso para as aulas. Comumente atrelada ao ensino de leitura, a literatura pode ser usada através de estratégias como a recriação de cenas das histórias para ilustrar aspectos culturais; redimensionamento de episódios no contexto do país do aprendiz; tradução do enredo da história para outras linguagens, a exemplo dos quadrinhos, da fotografia ou mesmo de produções em vídeo; cartas de encorajamento, conselho, alerta ou reprovação a personagens; atualização temporal das narrativas; diálogos entre personagens de diferentes textos literários; criação de representações pictóricas de poemas, usando imagens do lugar onde os aprendizes vivem; entrevistas entre personagens de textos literários diferentes, apenas para citar alguns exemplos.

Tão importantes quanto as estratégias de ensino são as temáticas dos textos literários. Quando inseridos em contexto pós-colonial e, sobretudo, se produzidos por escritores negros, esses textos podem apresentar aos aprendizes questões que levam ao exercício de projeção, empatia e conhecimento sobre experiências outras e que se fazem outras em virtude do predomínio do acesso a um mesmo tipo específico e privilegiado de experiência que, há séculos, aponta para o Norte. A partir do contato com textos literários, especialmente os produzidos fora do Norte global, é possível ampliar o repertório cultural dos aprendizes e, mediante atividades de imersão nos textos, aguçar o pensamento crítico e o respeito à diversidade.

\section{CONCLUSÃO}

Enunciar ausências de grupos subalternizados, denunciar uma visão capitalista sobre a educação e argumentar a favor de um ensino decolonial concernem a diversas áreas de produção de saber e, neste ensaio teórico, receberam uma leitura sob a luz da Retórica 
tendo como interface os pressupostos da Análise de Discurso Crítica. A opção por esses dois campos resultou do objetivo de descortinar duas acepções sobre educação que apresentam diferenças em textos de escritores negros e não negros e, com isso, flagrar elementos persuasivos que incidem em diversos discursos, que auxiliam a disseminar e/ou manter padrões e conhecimentos. Enquanto a Retórica permite identificar os elementos de persuasão, a Análise de Discurso Crítica chama a atenção aos mecanismos de poder subjacentes aos lugares marcados pela colonialidade, entre os quais figuram contextos de ensino.

Para decolonizar a educação, este ensaio propôs estratégias de ensino de inglês através de textos literários, advogando pelo uso de textos produzidos no Sul Global, em especial, por escritores negros. A principal estratégia é a conscientização e, para colocá-la em cena, foram analisados textos literários que apresentam sujeitos cujas vidas são marcadas por experiências educacionais. A análise dos textos demonstrou diferenças nos sentidos da educação entre escritores negros e brancos. Essa diferença, embora pareça dicotômica, enuncia a importância de considerar questões raciais ao refletir sobre educação.

Com as considerações feitas neste ensaio, a expectativa é abrir fissuras em estruturas consolidadas e sustentadas pela ênfase em discursos hegemônicos em detrimento de uma diversidade de produções discursivas silenciadas pela colonialidade. Essa é, inegavelmente, uma questão de retórica e por isso mesmo imprescindível à cena acadêmica nos tempos atuais neste e em outros países afetados pela colonialidade, que se reinscreve, mas não é capaz de vetar o processo de reinvenção e resistência que sempre incidirá enquanto for possível ler, ensinar e viver literaturas.

\section{REFERÊNCIAS}

ACHEBE, Chinua. Home and Exile. Nova lorque: Anchor Books, 2000.

A Message from Chinua Achebe. In: THIONG’O, Ngũgĩ wa. Weep Not, Child. Johannesburg: Penguin Books, 2009

No Longer at Ease. Londres: Penguin Books, 2010.

ADICHIE, Chimamanda Ngozi. The Danger of a Single Story. TEDGlobal 2009, [S. I.], 2009. Disponível em: https://www.ted.com/talks/chimamanda_adichie_the_danger_of_a_single_story/transcript?language=pt. Acesso em: 10 nov. 2016.

ARISTÓTELES. Poética. São Paulo: Editora Nova Cultural Ltda, 1996.

BASSO, Daniela; NETO, Luiz Bezerra. As influências do neoliberalismo na educação brasileira: algumas considerações. In: Itinerarius Reflectionis: Revista Eletrônica de Pedagogia do Campus Jataí - UFG, v. 1, n. 16 , 2014. Disponível em: <https://www.revistas.ufg.br/rir/article/view/29044/17224>. Acesso em 10 set. 2017.

BRASIL. LEI N 10.639, de 9 de janeiro de 2003. Diário Oficial da União, Brasília, DF, Ano CXL N. 8. p. 8. 10 de janeiro de 2003. Seção 1. p.1. Disponível em:

<http://www.planalto.gov.br/ccivil_03/leis/2003/L10.639.htm>. Acesso em: 3 jan. 2019. 
BRASIL. LEI N 11.645, de 10 março de 2008. Diário Oficial da União, Brasília, DF, 2008. Disponível em:

<http://www.planalto.gov.br/ccivil_03/_ato2007-2010/2008/lei/111645.htm>. Acesso em: 3 jan. 2019.

COETZEE, J. M. Youth. Londres: Vintage Books, 2003.

FAIRCLOUGH, Norman. Análise Crítica do Discurso como método em pesquisa social científica. Tradução Iran Ferreira de Melo, Linha D’Água, v. 25, n. 2, São Paulo: USP, 2012, p. 307-329. Routledge, 2013

Critical Discourse Analysis: the Critical Study of Language. 2. ${ }^{a}$ ed. Londres e Nova lorque:

FIORIN, José Luiz. Elementos de análise do discurso. São Paulo: Contexto, 2018a.

Figuras de Retórica. São Paulo: Contexto, 2018b.

FREIRE, Paulo. Pedagogia do Oprimido. Rio de Janeiro: Paz e Terra, 2011.

GHOSN, Irma K. Nurturing Emotional Intelligence through Literature. English Teaching Forum, 2001, vol. 39, n. 1. Disponível em: <https://americanenglish.state.gov/files/ae/resource_files/01-39-1-c.pdf>. Acesso em 2 jan. 2019.

GIROUX, Henry A. Neoliberalism's War on Higher Education. Chicago: Haymarket Books, 2014.

HOOKS, Bell. Teaching Community. a Pedagogy of Hope. Nova lorque: Routledge, 2003.

Teaching Critical Thinking: Practical Wisdom. Nova lorque e Londres: Routledge, 2010.

JENSEN, E. Teaching with Poverty in Mind: What Being Poor Does to Kids' Brains and What Schools Can Do About It. Alexandria, Virginia: ASCD, 2009.

MAGALHÃES, Izabel; MARTINS, André Ricardo; RESENDE, Viviane de Melo. Análise de Discurso Crítica: um método de pesquisa qualitativa. Brasília: Editora Universidade de Brasília, 2017.

MBEMBE, Achille. Crítica da Razão Negra. Tradução Marta Lança. Lisboa: Portugal, 2014.

MELO, Ivan Ferreira de. Histórico da análise de discurso crítica. In: BATISTA, José Ribamar Lopes; SATO, Denise Tamaê Borges (Org.). Análise de discurso crítica para linguistas e não linguistas. São Paulo: Parábola, 2018, p. 20-35.

MIGNOLO, Walter. What Does It Mean to Decolonize?. In: MIGNOLO, Walter; WALSH, Catherine E (Editors). On Decoloniality. Concepts, Analytics, Praxis. Durham and London: Duke University Press, 2018, p. 106-134.

MOTA, Fernanda. Literatura e(m) ensino de língua estrangeira. Revista Folio, vol. 2, n.1. Janeiro./jun.2010. Disponível em: <http://periodicos.vesb.br/index.php/folio/article/view/39>. Acesso em 19 fev. 2019.

OLIVEIRA, Luiz Fernandes de. Educação e Militância Decolonial. Rio de Janeiro: Selo Novo, 2018.

PEREIRA, Fernanda Mota. Educação em narrativas: experiências em contextos de aprendizagem. Projeto de Pesquisa. Instituto de Letras, Universidade Federal da Bahia, 2016.

Pedagogy of Possibility In Foreign Language Classrooms Through Literature and Other Media In Brazil and Beyond. Revista Estudos Linguísticos e Literários. N. 57, jul-dez 2017, Salvador, p. 23-37.

PLATÃO. A República. São Paulo: Editora Nova Cultural, 2000.

REBOUL, Olivier. Introdução à retórica. Tradução Ivone Castilho Beneditti. São Paulo: Martins Fontes, 2000.

RIBEIRO, Djamila. Lugar de fala. São Paulo: Sueli Carneiro; Pólen, 2019.

SANTOS, Boaventura de Sousa. Fim do império cognitivo: a afirmação das epistemologias do Sul. Belo Horizonte: Autêntica Editora, 2019. 
SAUNANA, John. The Alternative. Honiara: The Government Printer, 1980.

SHAW, George Bernard. Pygmalion. Sweden: Wisehouse Classics, 2016.

THIONG’O, Ngũgĩ wa. Weep Not, Child. Johannesburg: Penguin Books, 2009.

VAN-DIJK, Teun A. Racism and Discourse In Latin America: an Introduction. In: (Ed.). Racism and Discourse in Latin America. Traduzido por Elisa Barquin and Alexandra Hibbett. Lanham: Lexington Books, 2009, p. 1-10.

WALSH, Catherine. On Decolonial Dangers, Decolonial Cracks, and Decolonial Pedagogies Rising. In: MIGNOLO, Walter; WALSH, Catherine E (editors). On Decoloniality. Concepts, Analytics, Praxis. Durham and London: Duke University Press, 2018, p. 81-98.

WRIGHT, Erik Olin. Como ser um anti-capitalista no século XXI? Tradução Fernando Cauduro Pureza. São Paulo: Boitempo, 2019. 